\title{
PSICOLOGIA POLÍTICA E A POTÊNCIA TRANSFORMADORA DO ESPAÇO ESCOLAR
}

\section{Political Psychology and the transformative power of the school space}

\author{
Jean Costa Santana - Universidade Federal do Rio de Janeiro/Brasil
}

\begin{abstract}
RESUMO: O presente artigo objetiva discutir o espaço escolar através da interdisciplinaridade da psicologia política. Nesse sentido, buscamos contribuir para um espaço escolar que crie processos de emancipação social e se comprometa, cada vez mais, com a realidade social dos alunos e das maiorias populares oprimidas. Da perspectiva interdisciplinar da psicologia política, como referencial teórico e metodologia, tentamos analisar e discutir elementos psicopolíticos que habitam a instituição escolar, e apresentar concepções de uma psicologia politizada e libertadora, conforme a orientação teórica e prática de Martín-Baró. Para essa análise, não autonomizamos a instituição escolar, separando-a da sociedade, mas a situamos como parte de uma totalidade que se organiza mediante o conjunto das relações sociais sob o capitalismo. E a partir da nossa discussão, concluímos que o espaço escolar possui muitas contradições, justamente porque é um espaço formado por elementos políticos, psicológicos, afetivos e sociais, e também pelo seu potencial de propagar esses elementos. E devido essa importância, é um espaço frequentemente disputado pelo governo, por movimentos populares, por formas de agenciamentos conservadores e reacionários, ou por outras maneiras críticas e revolucionárias. Portanto, reconhecemos que o espaço escolar é um espaço de luta; e como espaço ativo e vivo, por causa de homens e mulheres que o compõem, há a imprescindível necessidade desse espaço estar implicado e comprometido com a transformação social, que tanto necessita nossas populações.
\end{abstract}

Palavras-chave: Espaço Escolar. Emancipação Humana. Martín-Baró. Psicologia Política.

ABSTRACT: This article aims to discuss the school space through the interdisciplinarity of political psychology. In this sense, we seek to contribute to a school space that creates processes of social emancipation and is increasingly committed to the social reality of students and oppressed popular majorities. From the interdisciplinary perspective of political psychology, as a theoretical framework and methodology, we try to analyze and discuss psychopolitical elements that inhabit the school institution, and to present conceptions of a politicized and liberating psychology according to Martín-Baró's theoretical and practical orientation. For this analysis, we do not make the school institution autonomous by separating it from society, but situate it as part of a totality that is organized through the set of social relations under capitalism. And from our discussion, we conclude that the school space has many contradictions precisely because it is a space formed by political, psychological, affective and social elements, and also by its potential to propagate these elements. And because of this importance, it is a space often disputed by government, popular movements, conservative and reactionary forms of agency, or other critical and revolutionary ways. Therefore, we recognize that the school space is a space of struggle; and as an active and living space, because of the men and women who

Educação, Psicologia e Interfaces, Volume 4, Número 1, p. 175-189, Janeiro/Março, 2020.

ISSN: 2594-5343. DOI: https://doi.org/10.37444/issn-2594-5343.v4i1.178 
compose it, there is the indispensable need for this space to be implicated and committed to the social transformation that our populations so badly need.

Keywords: School Space. Human Emancipation. Martín-Baró. Political Psychology.

\section{INTRODUÇÃ̃O}

Neste artigo, fizemos uso da Psicologia Política visando contribuir para uma formação escolar conflitiva, problematizadora e crítica. Para isso, partimos do seguinte problema: como a Psicologia Política pode contribuir na construção de uma escola que reconheça e fomente processos de emancipação e libertação social?

Sendo assim, discutimos o espaço escolar, como microsociedade indissociável da organização política e econômica (APPLE, 2006). Nesse espaço, há avanços e retrocessos em meio a investimentos reacionários ou progressistas, compostos por questões políticas, comportamentais e afetivas. E a psicologia política, como ferramenta de análise dos discursos dominantes que permeiam os espaços sociais (PARISÍ, 2016), possibilita discutir o espaço escolar de forma crítica e libertadora.

Este artigo foi produzido através de pesquisa bibliográfica. Segundo Lakatos e Marconi (1999) a pesquisa bibliográfica é o primeiro passo de quase todas as pesquisas, e algumas são desenvolvidas, exclusivamente, por esse meio. Essa forma de pesquisa possibilita ao pesquisador e, posteriormente, ao leitor, tomar conhecimentos das principais teorias, concepções e descobertas do tema estudado.

Sendo assim, a partir da interdisciplinaridade da Psicologia Política, buscamos entender a instituição escolar, através do materialismo histórico-dialético. Sendo assim, não excluímos a instituição escolar das contradições sociais da sociedade de classes. Partimos, no entanto, da realidade material e histórica, na qual os seres humanos criam, produzem e reproduzem sua vida social. Mediante isso, nos adentramos numa determinação fundamental - que é o modo de produção capitalista. Nessa organização produtiva, há uma classe trabalhadora que produz, e outra classe, não-produtora, mas que se apropria privadamente do que foi socialmente produzido. A partir dessa relação social contraditória, para não se dizer antagônica, surgem formas jurídicas e políticas (dentro delas a instituição escolar) que buscam naturalizar, ocultar e regularizar essa relação (MARX, 1859/1997; VIANA, 2007; ENGUITA, 1989).

Educação, Psicologia e Interfaces, Volume 4, Número 1, p. 175-189, Janeiro/Março, 2020.

ISSN: 2594-5343. DOI: https://doi.org/10.37444/issn-2594-5343.v4i1.178 
Para além disso, o espaço escolar, atravessado por crises, pensamento crítico, forças criadoras e potências transformadoras, expressa a luta de classes (SNYDERS, 2005). E é nessa luta que a Psicologia Política, ao se posicionar ao lado dos oprimidos, oferece sua contribuição.

\section{UMA ANÁLISE DA INSTITUIÇÃO ESCOLAR}

Segundo Loural (1993) a ocupação e atuação nos espaços institucionais, envolvem implicações políticas que devem ser avaliadas conforme os sentidos e significados práticos da instituição. Para o autor, torna-se necessário problematizar a funcionalidade da instituição, que, entendida socialmente como natural, ampara-se em ordenamentos políticos que, no mínimo, necessitam de uma reflexão crítica sobre seus objetivos e sentidos sociais.

Hur (2016) ao descrever sobre formas de agenciamentos psicopolíticos entendidos como proposições que procuram compreender as articulações e os processos políticos nos diversos espaços institucionais -, conceitua duas formas de agenciamentos que são úteis para nossa análise: a estratopolítica e a tecnopolítica.

Nesse sentido, a instituição escolar, como espaço social, se configura como espaço político (APPLE, 2006), e a ligação entre a estratopolítica, a tecnopolítica e a escola, darse-á pelas formas de agenciamento presentes na instituição escolar, como espaço social e político. Sendo assim, por estratopolítica entende-se:

A estratopolítica é o agenciamento psicopolítico que corresponde às práticas políticas norteadas pela ocupação de lugares, fixação aos estratos e aos processos de institucionalização. $O$ investimento desejante é dirigido à fixação nos estratos institucionais, principalmente nos lugares e posições que conferem poder e traços identitários de status, na clássica configuração do 'amor ao poder'. Essa fixação tem como fim a extração de uma mais-valia política, institucional, simbólica, do estrato que se ocupa; fixar-se à terra e extrair seus bens, um extrativismo político (HUR, 2016, p. 110, grifos do autor).

No sentido da estratopolítica, inferimos que a instituição escola, como força social e relações de poder (MARTÍN-BARÓ, 1989), pode atuar na normatização, naturalização e captura de condutas que, em obediência aos estratos institucionais, reproduzem valores da sociabilidade capitalista.

Educação, Psicologia e Interfaces, Volume 4, Número 1, p. 175-189, Janeiro/Março, 2020.

ISSN: 2594-5343. DOI: https://doi.org/10.37444/issn-2594-5343.v4i1.178 
A educação institucionalizada pela escola, ou seja, fixa nos estratos da sociabilidade capitalista, produz formas de agenciamento que sustentam a reprodução das relações sociais, amparadas pelo currículo político dominante (BOURDIEU; PASSERON, 1992). Segundo Marx (1845-1846/2007) as ideias dominantes sempre serão, conforme os determinados modos de produção da vida social, as ideias da classe dominante; pois a classe que detém os meios produtivos, farão de suas ideias as ideias dominantes, e no regime burguês capitalista, o surgimento da instituição escolar, atua como superestrutura direcionada ao mercado de trabalho (Viana, 2007) como bem demonstra a Lei de Diretrizes e Bases da Educação Nacional, nº 9394/1996, art. $1^{\text {a }}$.

Assim, percebemos que a intenção da escola, como instituição, não estaria relacionada objetivamente com a emancipação crítica e libertária, mas sim a uma maneira escolarizada de interpretar racionalmente o conhecimento, submetido à funcionalidade acrítica dos objetivos institucionais (ILLICH, 1985). Isso envolve a construção de crenças aos marcos da legalidade burguesa, sem levar em conta sua ineficácia ${ }^{1}$, fissura e crise.

Pela estratopolítica, podemos apresentar a educação bancária de Paulo Freira (1987). Ela se assemelha à estratopolítica no sentido da conformidade, da reprodução, da manutenção e da perpetuação do poder pedagógico, submetido ao currículo político dominante da escola ${ }^{2}$. Dessa forma, o educador, trata os alunos como abstrações institucionais, e deposita uma aprendizagem com o fim de reproduzir o status quo dominante.

De acordo com Saviani (1999), a escola teria passado por três períodos, sendo eles: uma escola tradicional, como forma pedagógica pautada na adaptação e conformação dos alunos ao conteúdo imposto unilateralmente; uma escola nova, que nasceu como crítica a pedagogia tradicional, mas teve em seu modelo uma concepção individualista e individualizante; e uma escola tecnicista, que estabelecida no final do século XX, teve em sua forma uma pedagogia transferida para a eficiência e rendimento produtivo, foi inspirada na neutralidade científica e na racionalidade, na eficiência e na produtividade, e indissociável ao contínuo processo de maximização e otimização do conhecimento funcional e técnico.

Acerca da produção técnica da instituição escolar, o segundo conceito de agenciamento psicopolítico de Hur (2016), sustenta que:

Educação, Psicologia e Interfaces, Volume 4, Número 1, p. 175-189, Janeiro/Março, 2020.

ISSN: 2594-5343. DOI: https://doi.org/10.37444/issn-2594-5343.v4i1.178 
A tecnopolítica é o agenciamento psicopolítico que não corresponde mais à fixação aos estratos nem à ocupação de cargos políticos, ela coloca ênfase na técnica e nos saberes para a gestão da vida e da política. Portanto, não está mais centrada na antiga liderança política, carismática e legitimada pelo partido e pelas massas, mas, sim, no pensador-técnico que assume o discurso competente do bom gestor. (...) Não interessa quem ocupa o lugar de gestão institucional, são relevantes as metodologias e procedimentos que se adotam para uma melhor eficácia da racionalidade governamental (HUR, 2016, p. 112).

Dessa forma, essa nova maneira de agenciamento psicopolítico, é entendida no contexto atual de transformações que vive a sociedade e as instituições. E no capitalismo, há uma lógica de funcionamento que "consiste na incitação à produtividade, competitividade, livre iniciativa e atualização da lógica privada e do acúmulo" (HUR, 2015, p. 235). Consequentemente, a instituição escolar, não se escapa dessa lógica, pois ela está submetida às determinações sociais segundo a lógica do modo de produção capitalista (ENGUITA, 1989), cujo fetichismo da técnica, atua no distanciamento de processos educativos emancipatórios (ADORNO, 1995)

A instituição escolar, é altamente eficaz na dissimulação das necessidades sociais e humanas pela construção de discursos que ocultam e não analisam as contradições sociais da sociedade. Há a necessidade de combater o racismo, o sexismo, a homofobia, a discriminação contra os deficientes e a opressão contra os pobres, assim como há a necessidade de problematizar a realidade social e política que perpassa a luta de classes; no entanto, a instituição escolar, tem como prioridade o inculcamento de discursos direcionados à socialização e à preparação da mão de obra ao mercado de trabalho (APPLE, 2006).

\section{A INVESTIDA REACIONÁRIA SOBRE O ESPAÇO ESCOLAR}

Semelhante as novas formas de objetivação e subjetivação, segundo as determinações do capital que interpenetram no espaço escolar, Apple (2003) esclarece que uma nova conjectura estrutural político-econômica mundial, emerge sobre o espaço escolar ${ }^{3}$. Em prol do avanço das forças econômicas, ditadas pelas políticas neoliberais, há a reunião de forças que Apple (2003) denominou como "modernização conservadora". Trata-se de uma aliança poderosa de grupos a favor de uma educação conservadora e direcionada para os fins econômicos.

Educação, Psicologia e Interfaces, Volume 4, Número 1, p. 175-189, Janeiro/Março, 2020.

ISSN: 2594-5343. DOI: https://doi.org/10.37444/issn-2594-5343.v4i1.178 
Nessa lógica, as escolas estariam se transformando, além de um espaço reacionário, numa espécie de mercado produtivo, onde a disciplina, o caráter e a eficiência seriam os fundamentos pedagógicos.

Segundo Apple (2003), a modernização conservadora é formada pela junção de grupos como: os neoliberais, os neoconservadores e os populistas autoritários. Todo esse seguimento ultraconservador visa frear ainda mais a lacuna aberta pelo espaço político dentro da escola, de modo que não haja mais formas reivindicatórias e o posicionamento subversivo na atmosfera escolar.

Sobre o grupo dos neoliberais, Apple (2003) esclarece:

Para os neoliberais, há uma forma de racionalidade que é mais potente do que qualquer outra - a racionalidade econômica. A eficiência e uma "ética" da análise custo-benefício são as normas dominantes. Todas as pessoas devem agir de forma a maximizar seus próprios benefícios pessoais. $\mathrm{Na}$ verdade, por trás dessa posição está uma afirmação empírica de que é assim que todos os sujeitos racionais agem (APPLE, 2003, p. 44).

Nessa esteira, o autor sustenta que os neoconservadores cultuam e romantizam o passado e buscam na escola a ordem e o controle, e, além disso, atacam o multiculturalismo e lutam contra toda forma de ensino inclusivo que envolvam políticas afirmativas ou matrizes curriculares alternativas.

Já os populistas autoritários, são as organizações populares coletivas que teriam um fim em comum. Esse fim seria a luta contra os progressos que atingiram o campo da educação, como as políticas de gênero, o currículo étnico-racial, a perspectiva feminista e a inclusão de deficientes; os populistas autoritários, representam uma direita conservadora que está atrelada aos religiosos fundamentalistas, e juntos sustentam um discurso autoritário, moralista e familista (APPLE, 2003).

A modernização conservadora avança no espaço escolar, e contra seus discursos ideológicos, não basta uma psicologia escolar que tenha como intenção a mera adaptação do aluno à escola. Ao contrário, torna-se necessário a perspectiva crítica de uma psicologia politizada, que ao avaliar o espaço escolar, contribua com um olhar crítico e emancipatório. É nesse sentido que a psicologia política atua como um dispositivo de análise da realidade, dos discursos nos espaços e nas interações sociais, denunciando sua motivação política-ideológica (PAVÓN-CUÉLLAR, 2016).

Educação, Psicologia e Interfaces, Volume 4, Número 1, p. 175-189, Janeiro/Março, 2020.

ISSN: 2594-5343. DOI: https://doi.org/10.37444/issn-2594-5343.v4i1.178 
A psicologia política é um recurso eficaz na denúncia dessas novas formas de poder que avançam sobre o espaço escolar. Nesse sentido, pode atuar politicamente pela compreensão e revelação desses discursos que compõem as práticas educacionais dentro da escola.

A desconstrução de discursos da ideologia dominante, pela Psicologia Política, está na revelação de um dos objetivos tácitos da instituição escolar, que segundo Illich, seria "esconder tão bem de seus participantes a profunda discrepância entre os princípios sociais e a realidade social do mundo de hoje" (ILLICH, 1985, p.56).

Todos os processos pelos quais passou a escola, e todas as investidas reacionárias que foram descritas, apenas confirmam a importância política que é o espaço escolar; sendo assim, a escola é um campo social em disputa permeado por forças contraditórias. O espaço escolar, entretanto, é um espaço dinâmico e mutável porque é composto por pessoas que têm concepções políticas diferentes; e mesmo que a escola seja atravessada pela hegemonia do sistema capitalista, há a necessidade de novas forças que procurem questionar e problematizar a educação estratificada e institucionalizada na escola.

\section{A PSICOLOGIA POLÍTICA E O ESPAÇO ESCOLAR}

A Psicologia Política, como campo interdisciplinar e heterogêneo, aborda os acontecimentos sociais, as ordenações políticas e os processos psicológicos (Montero,2009). A Psicologia Política, é uma área ampla e difusa, e tem como recurso metodológico teorias que articulam os processos psicológicos aos fenômenos políticos, e busca entender como os fenômenos políticos atuam nos processos psicológicos (SABUCEDO, 1996; MONTERO, 2009, PARISÍ, 2016).

As raízes da Psicologia Política, surgiram em meados do século XIX com autores como Marx, Durkheim, Le Bon que abordaram estudos sobre a ciência política articulada a elementos psicológicos (MOYA; MORALES, 1988). E, a partir dessa área, os estudos sociais permeados por fenômenos psíquicos, como nos trabalhos de Le Bon sobre a gestão das massas na França, ou de Durkheim sobre os acontecimentos sociais de sua época, contribuíram para as bases teóricas da Psicologia Política (MOYA; MORALES, 1988; SABUCEDO, 1996). 
Já no século XX, a Psicologia Política, ainda em formação, obteve outras contribuições que vieram da Teoria Crítica da Escola de Frankfurt, da psicologia behaviorista ou da psicanálise (SABUCEDO, 1996; GARZÓN,2008). E em meio a extrema instabilidade política e social, envolta de embates ideológicos, mudanças sociais, crises e guerras, não obstante, nesse período houve uma aproximação ainda maior entre a psicologia e a política na tentativa de buscar respostas aos acontecimentos políticos e sociais no século XX.

Na América Latina, contudo, a Psicologia Política foi redefinida conforme as necessidades geopolíticas de um continente submetido à colonização e ao imperialismo. E por perceber elementos políticos e psicológicos, decorrentes de um contexto histórico de repressão política, a psicologia política latino-americana analisou, além de outros elementos, a opressão social, o racismo estrutural, sistemas políticos ditatoriais, a consciência política, a ideologia, o trauma político decorrente das guerras e o papel social da psicologia e do psicólogo (MONTERO, 1987). Nessa direção, Montero (1991) destaca que, a partir da década de 80, a Psicologia Política latino-americana se debruçou sobre tarefas específicas direcionadas aos sentidos e aos efeitos dos fenômenos psicológicos manifestos nos diversos espaços políticos.

A Psicologia Política na América Latina foi fortemente influenciada pela perspectiva libertadora e emancipatória de Ignácio Martín-Baró ${ }^{4}$ (HUR; SABUCEDO; ALZATE, 2018; MONTERO, 1991; PAVÓN-CUÉLLAR, 2016; LACERDA JR., 2017). Martín-Baró acreditava que a Psicologia poderia oferecer contribuições para compreender a dinâmica, a história e o movimento da sociedade latino-americana. Mas para um diálogo entre a psicologia e a realidade política da América Latina, era necessário, primeiro, uma libertação da própria psicologia (MARTÍN-BARÓ, 1986). Nessa direção, Martín-Baró percebeu a ineficácia de modelos de uma psicologia construída dentro de laboratórios assépticos, supostamente apolítica, e presa ao contexto euro-estadunidense.

Para Martín-Baró (1986), a psicologia na América Latina, em seu campo teóricoconceitual e metodológico, estava amarrada em perspectivas que não dialogavam com a realidade da América Latina. A escravidão dessa psicologia se assentava num mimetismo cientificista, numa carência de epistemologia adequada à geopolítica latino-americana, e no dogmatismo provinciano (MARTÍN-BARÓ, 1986).

Educação, Psicologia e Interfaces, Volume 4, Número 1, p. 175-189, Janeiro/Março, 2020.

ISSN: 2594-5343. DOI: https://doi.org/10.37444/issn-2594-5343.v4i1.178 
Sobre o mimetismo cientificista, o psicólogo espanhol destacou uma psicologia preocupada com a reprodução de modelos experimentais e conceituais norte-americanos para dar-lhe um status científico, do que com o compromisso social com os povos latinoamericanos.

Martín-Baró (1986) expõe a falta de uma epistemologia adequada como parte do campo teórico da psicologia na América Latina, que se assentou no a-historicismo, no individualismo e numa visão homeostática da realidade social. À psicologia faltava, então, uma teoria que partisse de sua própria realidade histórico-social. Ao perceber isso, Martín-Baró apontou que pelo caminho do a-historicismo, a psicologia, ao desconsiderar as distintas realidades históricas e materiais como formas de constituição psicossocial, universalizou e naturalizou a natureza humana. E amparando-se em testes como a escala de medida de inteligência de Stanford-Binet ${ }^{5}$, procurou medir sob pressupostos padronizados, o grau de inteligência de um camponês ou de um aluno latino-americano, sem levar em conta o conceito de inteligência como construção histórica e social $^{6}$ (MARTÍN-BARÓ, 1986). Pela perspectiva individualista, a psicologia reduziu problemas estruturas a problemas interpessoais, e atribuiu ao indivíduo a responsabilidade por suas condições sociais, econômicas e emocionais (MARTÍN-BARÓ,1986). Na escola, esse processo ocorre quando há a chancela de culpa individual pela ação do profissionalpsicólogo, este indiferente às condições do aluno que são de ordem e causa social. Já a crença numa homeostase social, nos levou a ter receio de tudo que representa mudança ou desiquilíbrio, e a psicologia, ao acentuar como mal tudo aquilo que representa ruptura ou crise, classificou os "desiquilibrados" com transtorno de personalidade (como o transtorno de oposição desafiante descrito no DSM-5), assim como aqueles que buscam romper com a ordem social, foram descritos com algum tipo de diagnóstico negativo (MARTÍN-BARÓ, 1986).

No dogmatismo provinciano, Martín-Baró (1986) sustenta que a psicologia dependente, ou seja, colonizada, estaria presa em falsos dilemas teóricos que não levariam em nada, a não ser a posturas dogmáticas, limitadas por um espírito academicista indiferente ao compromisso científico de dar respostas à realidade latino-americana. E, logicamente, ao espaço escolar. 
Contudo, conforme Martín-Baró (1971), o psicólogo escolar tem como trabalho propor modelos e técnicas que fomente práticas viáveis à transformação do espaço escolar; isso por meio de uma psicologia que seja individual e social, e dialogue tanto com o aluno quanto ao espaço social que ele se inseri.

Nessa direção, Martín-Baró (1971) destaca a capacidade de diálogo do professor para escutar as autênticas necessidades de seus alunos, e se adentrar radicalmente no mundo pessoal do educando; um educador, cuja autoridade não seja pelo papel institucional, senão por sua realidade pessoal e capacidade de leitura crítica do mundo; que considera a motivação intrínseca do aluno e estimule sua capacidade de sujeito transformador do mundo; e crie um espaço escolar, onde a liberdade se aprende pelo próprio exercício da liberdade, e não por teorizações distantes da realidade social e do que fazer coletivamente.

Nessa esteira, destacamos a necessidade de se criar, no espaço escolar, um movimento artístico, como oficinas, apresentações teatrais, elaborações coletivas e comunitárias, para que a potência dos afetos seja liberada e proporcione uma espécie de micropolítica do cuidado.

Martín-Baró (1971), ainda destaca a utilidade de programas de estudos, fundados na diversidade pessoal dos alunos e abertos à "improvisação" do potencial criativo e crítico. As aulas devem partir de problemáticas reais, que incluam a sociedade, a família, grupos sociais, a religião ou a política, e sobre essas necessidades, se produza atividades e reflexões. Outro elemento de um espaço escolar emancipador para Martín-Baró (1971), é a escuta do pensamento divergente, assim se estabelecerá, no aluno questionador, um padrão de segurança psíquica e, ao mesmo tempo, a liberação de suas implicações pessoais e coletivas.

\section{CONSIDERAÇÕES FINAIS}

Percebemos que a diversidade teórica da Psicologia Política possui concepções importantes na análise e compreensão de fenômenos que envolvem a construção de subjetividades e objetividades dentro do campo escolar. Nesse sentido, a partir da psicologia política, tentamos discutir o espaço psicopolítico da escola através da crítica contra as investidas hegemônicas a esse espaço.

Educação, Psicologia e Interfaces, Volume 4, Número 1, p. 175-189, Janeiro/Março, 2020.

ISSN: 2594-5343. DOI: https://doi.org/10.37444/issn-2594-5343.v4i1.178 
Os problemas da escola passam pela compreensão dos problemas no âmbito estrutural, institucional e social. No âmbito estrutural, destacamos o sistema capitalista e seu ordenamento das relações sociais na escola; no âmbito institucional, expomos a cumplicidade e interrelação da instituição escolar como força operante na adaptação à ordem social; e no social, sustentamos a necessidade de crise e luta no espaço escolar, já que este é atravessado por políticas reacionárias que lutam contra seu papel transformador.

Portanto, a força transformadora do espaço escolar está em considerar o mundo circundante e social da criança, do adolescente e do adulto, numa aprendizagem que proponha reflexões sobre a realidade social. Isso se dará por meio de uma aprendizagem que penetre no mundo problemático do aluno, e lhe possibilite compreender seus problemas a partir dos problemas do mundo. O aluno, considerado como síntese do coletivo, e não um indivíduo isolado e culpado por seu fracasso, deve ser o principal objetivo de um espaço escolar crítico e emancipatório.

Esse potencial crítico e emancipador, somente pode ser materializado por aqueles que confrontem os estratos da instituição e que não se capitulem à educação para fins econômicos ou apolíticos. Esses entendem que o espaço escolar é um espaço de luta e de transformação social, onde deve ser garantido a fluidez do conhecimento para a autonomia social, política, e, sobretudo, humana.

\section{Notas de rodapé}

${ }^{1}$ Os marcos da legalidade burguesa são representados pela democracia, pela cidadania e pelo Estado de direito que asseguram crenças em universais abstratos como liberdade, igualdade e direito à propriedade. Para mais críticas aos marcos da legalidade burguesa, conferir Lacerda Jr. 2016; Chasin, 1978 e Viana, 2003.

2 Apple (2009) sustenta que o espaço escolar, embora sendo um espaço de luta e embates ideológicos, oculta certas determinações curriculares projetadas na conservação de políticas conservadoras e reacionárias.

${ }^{3}$ No contexto brasileiro, faz parte dessa conjuntura o Projeto de Lei Escola Sem Partido, $\mathrm{n}^{\circ}$ $867 / 2015$, e a militarização das escolas públicas. Esses projetos baseiam-se numa ênfase disciplinar que exclui visões de mundo conflitivas, reflexivas ou críticas.

${ }^{4} \mathrm{Na}$ América Latina a Psicologia da Libertação surge nos trabalhos de Ignácio Martín-Baró que, fortemente influenciado pela pedagogia libertadora de Paulo Freire, buscou enfrentar condições de injustiça e desigualdades sociais e construir processos de libertação e emancipação humana. Martín-Baró foi um psicólogo espanhol que sob o ambiente tóxico da ditadura de Franco, resolveu ingressar na Companhia de Jesus e realizar missões religiosas pelo mundo. Para além da decisão

Educação, Psicologia e Interfaces, Volume 4, Número 1, p. 175-189, Janeiro/Março, 2020.

ISSN: 2594-5343. DOI: https://doi.org/10.37444/issn-2594-5343.v4i1.178 
religiosa, Martín-Baró obteve uma sólida formação intelectual nos diversos ramos das ciências humanas: graduou-se em filosofia, na Colômbia, Teologia, na Bélgica, e psicologia em El Salvador; e mestrado e doutorado em ciências sociais na Universidade de Chicago nos Estados Unidos. Martín-Baró se fixou em El Salvador e desenvolveu suas pesquisas na Universidad Centroamericana José Simeon Cañas, e pelo seu posicionamento crítico frente a política imperialista norte-americana, colocada em prática pelo governo oligárquico de Alfredo Cristiane, foi executado, covardemente, em 1989, junto com mais 5 jesuítas e duas trabalhadoras pelo tropa de elite do exército salvadorenho a mandato do governo dos Estados Unidos. Para mais informações sobre a vida e obra desse autor, conferir os trabalhos de Lacerda Jr., (2017) que oferece uma ampla coletânea de textos traduzidos de Martín-Baró.

${ }^{5}$ No século XX a exigência de medição e classificação pela psicologia teve sua origem na França por Alfred-Binet, na suíça por Eduard Claparède, na Alemanha por Karl Gross e nos Estados Unidos por Mark Baldwin e James McKeen Cattell; todos eles buscaram na psicologia promover na escola a adaptação do estudante ao seu meio social conforme a nova organização social, política e econômica advinda da Revolução Industrial (FERREIRA, 2016). Em solo norteamericano James McKeen Cattell, sob influência da psicologia diferencial e eugenista de Francis Galton, construiu os primeiros instrumentos de medição de inteligência criando um movimento de testes psicológicos; já no Brasil, os primeiros testes foram utilizados por Ulisses Pernambucano, incluindo, entre eles, o teste Binet-Simon e o Rorschach, e após a Revolução de 1930, o governo fez grande utilização dos testes que foram aplicados às crianças na escola, visando medir suas aptidões individuais e a homogeneização das salas de aula, e na seleção de trabalhadores como garantia de adaptação mais harmoniosa nos cargos de trabalho (CASTRO, JOSEPHSON; JACÓ-VILELA, 2013).

${ }^{6}$ Não temos a intenção de deslegitimar a aplicação de testes ou de outros métodos quantitativo a fim de explicar e provar a realidade objetiva que se analisa, mas criticamos a aplicação do teste como forma de individualização e exclusão social mediante a patologização do indivíduo na escola e em outros espaços sociais (PATTO, 1999). Os testes, quando usados como aparato normativo, tornam-se ferramenta de exclusão social se aplicados em realidades distintas a partir de parâmetros descontextualizados conforme interesses de discriminação social; assim, explicase a realidade pelos resultados que o teste produz onde a medição quantitativa e os "dados" tornam-se um fim em si mesmo e ocultam os processos históricos e sociais (MARTÍN-BARÓ, 1991/2013).

\section{REFERÊNCIAS BIBLIOGRÁFICAS}

ADORNO, Theodore. Educação e Emancipação. Rio de Janeiro, Paz e Terra, 1995.

APPLE, Michael W. Educando à direita: mercados, padrões, deus e desigualdade. Trad. Dinah de Abreu. São Paulo: Instituto Paulo Freire, 2003.

APPLE, Michael W. Ideologia e currículo. Trad. Vinícius Figueira - $3^{\mathrm{a} e d}$. Porto Alegre: Artmed, 2006.

BOURDIEU, Pierre; PASSERON, Jean Claude. A reprodução: elementos para uma teoria do sistema de ensino. $3^{\text {a }}$ ed. Rio de Janeiro: Francisco Alves, 1992.

CASTRO, Alexandre de Carvalho et al. Medir, Classificar e diferenciar. Em: JACÓVILELA, A.M., FERREIRA, A.A.L., PORTUGAL, F.T., (Orgs), História da psicologia: rumos e percursos. $3^{\mathrm{a}}$ ed. Rio de Janeiro: Nau, 2013. 
CHASIN, José. O integralismo de Plínio Salgado: forma de regressividade no capitalismo hiper-tardio. São Paulo: Livraria editora Ciências Humanas, 1978.

ENGUITA, Mariano Fernandez. A face oculta da escola: educação e trabalho no capitalismo. Porto Alegre: Artes Médicas, 1989.

FERREIRA, Artur Leal O múltiplo surgimento da psicologia. Em: Jacó-Vilela, A.M., Ferreira, A.A.L., Portugal, F.T., (orgs), História da psicologia: rumos e percursos. $3^{\mathrm{a}}$ ed. Rio de Janeiro: Nau, 2013. P. 19-51.

FREIRE, Paulo. Pedagogia do oprimido. $17^{\mathrm{a}}$ ed. - Rio de Janeiro: Paz e Terra, 1987.

GARZÓN, Adéla Pérez. Teoría y práctica de la psicología política. In: Revista quadrimestral del Colégio Oficial de Psicólogas de la Comunitat Valenciana, Valência, n. 93, p. 4-25, maio/agosto, 2008. Disponível em:

http://www.uv.es/garzon/adela/publicaciones/Teoria\%20y\%20Practica\%20de\%20la\%2 OPsic

ologia\%20Politica.pdf. Acesso em: 08 de setembro de 2019.

HUR, Domenico Uhng. Agenciamentos psicopolítico: estratopolítica, tecnopolítica e nomadopolítica. In: Psicologia política crítica: Insurgências na América Latina.

Campinas, SP: Alínea, 2016

HUR, Domenico Uhng. Corpocapital: códigos, axiomática e corpos dissidentes. Revista Lugar comum $\mathrm{N}^{\circ} 45$, p. 232-245. Dez.2015. Disponível em: http://uninomade.net/wpcontent/files_mf/145097712500Corpocapital;\%20c\%C3\%B3digos, \%20axiom\%C3\%A1 tica\%20e\%20corpos\%20dissidentes\%20-\%20Domenico\%20Uhng\%20Hur.pdf. Acesso em: 8 de setembro de 2019 .

HUR, Domenico Uhng; SABUCEDO, José Manuel; ALZATE, Monica. El giro político de la Psicología Política Latinoamericana: crítica, rol social y proyecto ético-político. In: Revista electrónica de Psicologia Política, ano, 16, Nº 41. Nov-Dez. 2018. Disponível em> https://www.researchgate.net/publication/329814259_El_giro_politico_de_la_Psicologi a_Poli

tica_Latinoamericana_critica_rol_social_y_proyecto_etico-politico Acesso em>15-092019.

ILLICH, Ivan. Sociedade sem escolas. Porto alegre: Deriva, 1985.

LACERDA Jr., Fernando. Colocando a Psicologia contra a ordem: introdução aos escritos de Ignácio Martín-Baró. In: Crítica e libertação na Psicologia: estudos psicossociais. Trad. Fernando Lacerda Jr., Petrópolis: Vozes, 2017.

LACERDA Jr., Fernando. Insurgência, Psicologia Política e Emancipação Humana. In: HUR, D. U.; LACERDA, J. F. (Orgs.). Psicologia Política crítica: insurgências na América Latina. Campinas, SP: Alínea, 2016. P. 49-63.

Educação, Psicologia e Interfaces, Volume 4, Número 1, p. 175-189, Janeiro/Março, 2020. ISSN: 2594-5343. DOI: https://doi.org/10.37444/issn-2594-5343.v4i1.178 
LOURAU, René. Análise Institucional e Práticas de Pesquisa. In: RODRIGUES, H. B. C. (Org.), René Loural na uerj. Rio de Janeiro: UERJ, 1993.

MARCONI, Marina Andrade; LAKATOS, Eva Maria. Técnicas de pesquisa. São Paulo: Atlas, 1999.

MARTÍN-BARÓ, Ignacio. El método em psicología política. (2003, Trad. Fernando Lacerda Jr.). O método em Psicologia Política. Rev. Psicologia Política, Vol. 13, No 28. $1991 / 2013$.

MARTÍN-BARÓ, Ignacio. Hacia una psicología de la liberación. El Salvador: UCA, 1986.

MARTÍN-BARÓ, Ignacio. Problemas actuales en psicopedagogia escolar. El Salvador: UCA, 1971.

MARTÍN-BARÓ, Ignacio. Sistema, grupo y poder: psicología social desde centroamérica II. El Salvador: UCA Editores, 1989.

MARX, Karl. Contribuição à crítica da economia política. Tradução de Florestan Fernandes. 2.ed. - São Paulo: Expressão Popular, 1859/1977.

MONTERO, Maritza. ¿Para qué Psicología Política? Revista Psicologia Política. Vol. 08 n$^{\circ}$ 18. p. 199-213. Nov. 2009. Disponível em:

http://pepsic.bvsalud.org/scielo.php?script=sci_arttext\&pid=S1519-

549X2009000200002 Acesso em: 18 de setembro de 2019.

MONTERO, Maritza. La psicología Política en América Latina, una revisión bibliográfica: 1956-1986. In: Montero, Maritza et al. (Orgs), psicología Política Latinoamericana. Caracas-Venezuela: Panapo, 1987.

MONTERO, Maritza. Una orientación para la psicología Política en América latina. Em: Revista Psicologia Política. no 3. p. 27-43. Out. 1991. Disponível em: https://www.uv.es/garzon/psicologia\%20politica/N3-2.pdf Acesso em: 20 de setembro de 2019.

MOYA, Morales; MORALES, Domínguez. Panorama histórico de la Psicología Política. In: SEOANE, J; RODRÍGUEZ, Á. (orgs). Psicología Política. Madrid: Pirámide, 1988.

PARISÍ, Helio Rodolfo. Crise e insurgência, controle da subversão e subversão do controle: o papel da psicologia política. In: Psicologia política crítica: Insurgências na América Latina. Campinas, SP: Alínea, 2016.

PATTO, Maria Helena. A produção do fracasso escolar: histórias de submissão e rebeldia. São Paulo: Casa do Psicólogo, 1999.

PAVÓN-CUÉLLAR, David. Para uma redefinição Marxista da Psicologia Política. In: HUR, D.U; LACERDA, Fernando Jr.. Psicologia Política Crítica; insurgências na América Latina. Campinas, SP: Alínea. P. 33-47. 
SABUCEDO, J.M.C. La psicología política: antecedentes históricos y objeto de estudio. Psicología Política: aspectos conceptuales. Síntesis: Madrid, 1996.

SAVIANI, Demerval. Escola e democracia: teorias sobre educação. Campinas, SP: Autores Associados, 1999.

SYNDERS, Georges. Escola, classe e luta de classes. Trad. Leila Prado. São Paulo: Centauro, 2005.

VIANA, Nildo. A consciência da história: ensaios sobre o materialismo históricodialético. Rio de janeiro: Achiamé, 2007.

VIANA, Nildo. Estado, democracia e cidadania: a dinâmica da Política

Institucional no Capitalismo. Rio de Janeiro: Achiamé, 2003.

\section{Credenciais do autor}

SANTANA Jean Costa. Possui graduação em Psicologia pela Faculdade Anhanguera de Anápolis, Mestre em Psicologia Pela Universidade Federal de Goiás e doutorando em Psicologia pela Universidade Federal do Rio de Janeiro. E-mail: jeansantanaprof@outlook.com

Endereço para correspondência: Jean Costa Santana. E-mail: jeansantanaprof@outlook.com

Como citar este artigo (Formato ABNT): SANTANA Jean Costa. Recontar-se em Contos: saberes e vivências em contações de histórias na Educação Não Formal. Educação, Psicologia e Interfaces, v. 4, n. 1, p. 175-189, 2020. DOI: https://doi.org/10.37444/issn-2594-5343.v4i1.178

Recebido: 05/10/2019.

Aceito: 20/12/2019. 